Research Paper

\title{
Regulation of cell death receptor S-nitrosylation and apoptotic signaling by Sorafenib in hepatoblastoma cells ${ }^{\text {is }}$
}

A. Rodríguez-Hernández ${ }^{\mathrm{a}, 1}$, E. Navarro-Villarán ${ }^{\mathrm{a}, 1}$, R. González $^{\mathrm{b}, 1}, \mathrm{~S}$. Pereira ${ }^{\mathrm{a}, 2}$, L.B. Soriano-De Castro ${ }^{\mathrm{a}, 1}$, A. Sarrias-Giménez ${ }^{\mathrm{a}, 2}$, L. Barrera-Pulido ${ }^{\mathrm{c}}$, J.M. Álamo-Martínez ${ }^{c, h}$, A. Serrablo-Requejo ${ }^{d}$, G. Blanco-Fernández ${ }^{\mathrm{e}}$, A. Nogales-Muñoz $^{\mathrm{c}}$, A. Gila-Bohórquez ${ }^{c}$, D. Pacheco ${ }^{f}$, M.A. Torres-Nieto ${ }^{g}$, J. Serrano-Díaz-Canedo ${ }^{c}$, G. Suárez-Artacho ${ }^{c}$, C. Bernal-Bellido ${ }^{\text {c }}$, L.M. Marín-Gómez ${ }^{\text {c }}$, J.A. Barcena ${ }^{\mathrm{b}}$, M.A. Gómez-Bravo ${ }^{\text {c,h }}$, C.A. Padilla ${ }^{\mathrm{b}}$, F.J. Padillo ${ }^{\mathrm{c}, \mathrm{h}}, \mathrm{J}$. Muntané ${ }^{\mathrm{c}, \mathrm{h}, *}$

\footnotetext{
${ }^{a}$ Institute of Biomedicine of Seville (IBiS), Hospital Universitario “Virgen del Rocío"/CSIC/Universidad de Sevilla, Av. Manuel Siurot s/n, 41013 Sevilla, Spain

${ }^{\mathrm{b}}$ Departament of Biochemistry and Molecular Biology, University of Cordoba, Instituto Maimónides de Investigación Biomédica de Córdoba (IMIBIC), 14071 Córdoba, Spain

"Department of General Surgery, Hospital Universitario "Virgen del Rocío" - "Virgen Macarena"/Instituto de Biomedicina de Sevilla (IBiS)/CSIC/Universidad de Sevilla, Sevilla, Spain

${ }^{\mathrm{d}}$ Hepato-Biliary Surgery Unit, Hospital Universitario “Miguel Servet”, Zaragoza, Spain

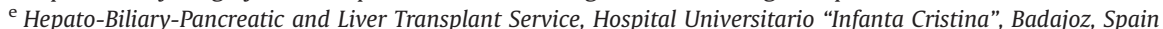

${ }^{\mathrm{f}}$ Department of General Surgery and Department of Pathology, Hospital Universitario "Rio Hortega", Valladolid, Spain

${ }^{\mathrm{g}}$ Department of Pathology, Hospital Universitario "Rio Hortega", Valladolid, Spain

${ }^{\mathrm{h}}$ CENTRO DE INVESTIGACIÓN BIOMÉDICA EN RED de Enfermedades Hepáticas y Digestivas (CIBERehd), Spain
}

\section{A R T I C L E I N F O}

Article history:

Received 18 June 2015

Received in revised form

17 July 2015

Accepted 20 July 2015

Available online 22 July 2015

\section{Keywords:}

Sorafenib

Hepatoblastoma

S-nitrosylation

NO

Apoptosis

Death-receptors

\begin{abstract}
A B S T R A C T
Nitric oxide (NO) plays a relevant role during cell death regulation in tumor cells. The overexpression of nitric oxide synthase type III (NOS-3) induces oxidative and nitrosative stress, p53 and cell death receptor expression and apoptosis in hepatoblastoma cells. S-nitrosylation of cell death receptor modulates apoptosis. Sorafenib is the unique recommended molecular-targeted drug for the treatment of patients with advanced hepatocellular carcinoma. The present study was addressed to elucidate the potential role of NO during Sorafenib-induced cell death in HepG2 cells. We determined the intra- and extracellular NO concentration, cell death receptor expression and their S-nitrosylation modifications, and apoptotic signaling in Sorafenib-treated HepG2 cells. The effect of NO donors on above parameters has also been determined. Sorafenib induced apoptosis in HepG2 cells. However, low concentration of the drug (10 nM) increased cell death receptor expression, as well as caspase-8 and -9 activation, but without activation of downstream apoptotic markers. In contrast, Sorafenib $(10 \mu \mathrm{M})$ reduced upstream apoptotic parameters but increased caspase-3 activation and DNA fragmentation in HepG2 cells. The shift of cell death signaling pathway was associated with a reduction of S-nitrosylation of cell death receptors in Sorafenibtreated cells. The administration of NO donors increased S-nitrosylation of cell death receptors and overall induction of cell death markers in control and Sorafenib-treated cells. In conclusion, Sorafenib induced alteration of cell death receptor S-nitrosylation status which may have a relevant repercussion on cell death signaling in hepatoblastoma cells.
\end{abstract}

(c) 2015 The Authors. Published by Elsevier B.V. This is an open access article under the CC BY license (http://creativecommons.org/licenses/by/4.0/).

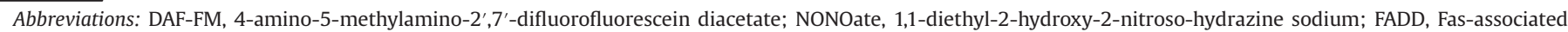

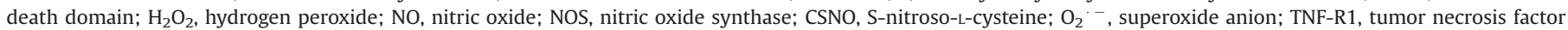
receptor type I; TRAIL-R1, tumor necrosis factor-related apoptosis-inducing ligand type I

This article belongs to a special issue on Nitric Oxide and Cancer, edited by Jordi Muntané and Benjamin Bonavida.

* Corresponding author at: Institute of Biomedicine of Seville (IBiS), Hospital Universitario "Virgen del Rocío"/CSIC/ Universidad de Sevilla, Av. Manuel Siurot s/n, 41013 Sevilla, Spain. Fax: + 34955923002 .

E-mail address: jmuntane-ibis@us.es (J. Muntané).

${ }^{1}$ Authors share co-first authorship

2 Authors share co-second authorship.
} 


\section{Introduction}

Nitric oxide (NO) is a lipophilic, highly diffusible, and shortlived physiological messenger [1]. NO is synthesized by three different gene-encoded NO synthases (NOS) in mammals: neuronal NOS (nNOS or NOS-1), inducible NOS (iNOS or NOS-2) and endothelial NOS (eNOS or NOS-3). The expression of NOS-2 is induced by inflammatory stimuli, while NOS-1 and NOS-3 are constitutively expressed [2]. NO regulates a variety of important physiological responses, including vasodilation, respiration, cell migration, immune response and apoptosis. Different clinical trials have demonstrated that the infusion of NO donors increases the effectiveness of chemotherapy and radiotherapy in patients with cancer $[3,4]$. NO appears to induce genotoxic lesions, and promotes angiogenesis, tumor cell growth, and invasion [5]. However, NO is able to exert antitumoral properties, as well as increase susceptibility to chemotherapy in different experimental in vivo and in vitro models [6].

The key hallmarks of cancer cells are unlimited replicative potential, insensitivity to growth-inhibitory signals, evasion of apoptosis, cellular stress, and sustained angiogenesis, invasiveness and metastatic potential [7]. The extension of several physiopathological mechanisms involved in cell proliferation, and homeostasis is limited by the co-activation of the cell death process [8]. The expression of proteins that promote cell proliferation and tumor progression requires the expression of antiapoptotic proteins or the inactivation of essential proapoptotic proteins in order to progress [9]. This assumption is confirmed by the finding that deregulated proliferation alone is not sufficient for tumor formation. The acquisition of resistance of tumor cells to apoptosis is an essential feature of cancer development. Cell death receptors, such as the tumor necrosis factor receptor type I (TNF-R1, p55, DR1), Fas/APO-1 (CD95, DR2), and tumor necrosis factor-related apoptosis-inducing ligand type I (TRAIL-R1, DR4) and type II (TRAIL-R2, DR5), are members of the tumor necrosis factor receptor (TNF-R) family. All members within the family are characterized by the presence of a cysteine-rich extracellular domain, which defines their ligand specificity $[10,11]$, and a cytoplasmic death domain of around 80 amino acids, which plays a central role in the activation of the caspase-dependent pathway and induction of apoptosis [12,13].

We [14] and others [15] have shown that NO sensitizes tumor cells by increasing cell death receptor expression on cancer cells. The post-translation modifications of the cell death receptors might promote or prevent its redistribution into lipid rafts and consequently, their susceptibility to cell death. In particular, proapoptotic stimuli, such as CD95L, induce an epidermal growth factor receptor (EGFR)-catalyzed tyrosine phosphorylation of CD95-death receptor in hepatocytes, as a prerequisite for CD95translocation to the plasma membrane, formation of the DISC and execution of apoptotic cell death [16]. In contrast, CD95 tyrosine nitration by peroxinitrite prevents its phosphorylation and cell death in Huh 7 cells [17]. NO donor or NOS-2 overexpression induces S-nitrosylation of Cys199 and Cys304, located in the cytoplasmic domain of CD95, increasing its migration to lipid raft and apoptosis in colon and breast cancer cells [18].

The administration of antitumoral agents, such as doxorubicin, cisplatin, adriamycin and bleomycin increases the expression of cell death receptors and/or their ligands, as well as other components of the cell death pathways such as Fas-associated death domain (FADD), pro-caspase-8, pro-caspase-3, the long isoform of pro-caspase-2 and Bax in different carcinoma cell lines [19-23]. Sorafenib, a multi-kinase inhibitor which inhibits proliferation and angiogenesis, is the recommended treatment for patients with locally advanced/metastatic hepatocarcinoma [24,25]. The increased susceptibility to cell death by Sorafenib is associated with down-regulation of cell survival pathways in hepatoma cells $[26,27]$. However, discrepancies exist regarding the regulation of extrinsic cell death pathways by Sorafenib in different tumor cell lines $[28,29]$. In addition, Sorafenib has been shown to dose-dependently induce oxidative stress, such as superoxide anion $\left(\mathrm{O}_{2}{ }^{-}\right)$, hydrogen peroxide $\left(\mathrm{H}_{2} \mathrm{O}_{2}\right)$ and $\mathrm{NO}$, in HepG2 cells [30]. The aim of the present study was to determine the capacity of Sorafenib to regulate the expression of cell death receptor and/or its S-nitrosylations, as well as extrinsic apoptotic signaling in hepatoblastoma cells. Data showed that the drug reduces S-nitrosylation of cell death receptors which was related to a shift from moderate extrinsic cell death pathway to drastic increase of downstream apoptotic markers in HepG2 cells.

\section{Material and methods}

\subsection{Materials}

All reagents were from Sigma-Aldrich Chemical Co. (St Louis, Missouri, USA) unless otherwise stated. 4-Amino-5-methylamino$2^{\prime}, 7^{\prime}$-difluorofluorescein diacetate (DAF-FM) was obtained from Molecular Probes (Cat. D-23842). S-nitroso-L-cysteine (CSNO) was prepared according to the procedure described elsewhere [31] by incubation of L-cysteine with acidified sodium nitrite and quantification by absorbance at $334 \mathrm{~nm}$ using a molar absorption coefficient of $0.74 \mathrm{mM}^{-1} \mathrm{~cm}^{-1}$. Sorafenib Tosylate was purchased from Carbosynth (Carbosynth Ltd., Berkshire, United Kingdom).The study protocol has been approved by the Ethical Committee of the Institution.

\subsection{Cell lines and culture conditions}

HepG2 cell line was obtained from the ATCC-LGC (Barcelona, Spain). Cells were negative for mycoplasma contamination. Cells were routinely maintained in EMEM (Eagle's Minimum Essential Medium) (Sigma-Aldrich Chemical Co) pH 7.4 supplemented with 10\% fetal bovine serum (F7524, Sigma-Aldrich, Lot No: 022M3395, endotoxin $<0.2 \mathrm{EU} / \mathrm{ml}$ ), $2.2 \mathrm{~g} / \mathrm{H} \mathrm{HCO}_{3} \mathrm{Na}, 1 \mathrm{mM}$ sodium pyruvate, $100 \mathrm{U} / \mathrm{ml}$ penicillin, $100 \mu \mathrm{g} / \mathrm{ml}$ streptomycin, $0.25 \mu \mathrm{g} / \mathrm{ml}$ amphotericin and the corresponding selection antibiotic in $5 \% \mathrm{CO}_{2}$ in air at $37^{\circ} \mathrm{C}$.

Cells were maintained for $24 \mathrm{~h}$ before administration of Sorafenib (0, $10 \mathrm{nM}$ and $10 \mu \mathrm{M})$. 1,1-Diethyl-2-hydroxy-2-nitroso-hydrazine sodium (NONOate) $(5 \mu \mathrm{M})$ or CSNO $(5 \mu \mathrm{M})$ was administered $30 \mathrm{~min}$ before Sorafenib, and maintained for $48 \mathrm{~h}$. The parameters were assessed at 12, 24 and $48 \mathrm{~h}$ after Sorafenib administration. Culture medium was replaced every $24 \mathrm{~h}$.

\subsection{Measurement of cell death}

Caspase-8, Caspase-9 and Caspase-3-associated activity were determined using Caspase-Glo ${ }^{\circledR}$ Assay Systems (G8201, G8211 and G8091, Promega, Madison, Wisconsin, USA). Cells were treated with Caspase-Glo ${ }^{\circledR}$ Reagent in an "add-mix-measure" format resulting in cell lysis, caspase-8-dependent cleavage of the substrate and generation of a "glow-type" luminescent signal. The signal generated is proportional to the amount of caspase activity. The values are extrapolated into a calibration curve included in the assay.

HepG2-fixed cells cultured in glass-Petri dish were used for measuring apoptosis by TUNEL assay (Promega, G3250). The assay measures the fragmented DNA of apoptotic cells by catalytically incorporating fluorescein-12-dUTP at 3'-OH DNA ends using the enzyme Terminal Deoxynucleotidyl Transferase (TdT), which forms a polymeric tail using the principle of the TUNEL assay. The 
fluorescein-12-dUTP-labeled DNA was visualized using an Olympus BX61 microscope. Fluorescence quantification was performed using Leica Application Suite Advanced Fluorescence software and ImageJ software.

\subsection{Expression of TNF-R1, CD95 and TRAIL-R1}

Cells were washed twice with PBS (with $\mathrm{Ca}^{2+}$ ) and treated with lysis buffer ( $50 \mathrm{mM}$ HEPES pH. 7.5, $150 \mathrm{mM} \mathrm{NaCl}, 5 \mathrm{mM}$ EDTA, 1\% NP-40) including $1 \mathrm{mM}$ PMSF, $1 \mathrm{mM} \mathrm{NaF}, 1 \mathrm{mM} \mathrm{Na}_{3} \mathrm{VO}_{4}$ and a commercial protease inhibitor cocktail containing AEBSF-HCl (Serine protease), Aprotinin (Serine protease), Bestatin (Aminopeptidase B and Leucine Aminopeptidase), E-64 (Cysteine protease), Leupeptine (Cysteine protease and trypsin-like serine proteases), Pepstatin A (Aspartic proteases) (P8340, Sigma-Aldrich Chemical Co.). Culture medium was collected and centrifuged for 5 min $4{ }^{\circ} \mathrm{C}$ at $400 \mathrm{~g}$, and detached cells transferred to cell lysate, and maintained for $20 \mathrm{~min}$ on ice with vortex each $5 \mathrm{~min}$. After centrifugation at $15,520 \mathrm{~g}$ for $5 \mathrm{~min}$ at $4{ }^{\circ} \mathrm{C}$, the supernatant was stored at $-20^{\circ} \mathrm{C}$ for the measurement of NO-end products. The expression of TNF-R1, CD95 and TRAIL-R1 protein expression were determined by SDS-PAGE coupled to Western-blot analysis. Proteins $(50-100 \mu \mathrm{g})$ were separated by $10-12 \%$ SDS-PAGE and transferred to PVDF membranes. The membranes were incubated with the corresponding commercial primary antibodies against TNF-R1 (1/250) (sc-7895, Santa Cruz Biotechnology Inc.), CD95 (1/ 250) (sc-715, Santa Cruz Biotechnology Inc.; Delaware, California, USA), and TRAIL-R1 (1/250) (sc-6823, Santa Cruz Biotechnology Inc.). The corresponding anti-rabbit (1/10000) (sc-2301, Santa Cruz Biotechnology, Inc.), anti-mouse (1/10000) (sc-2031, Santa Cruz Biotechnology Inc.,) or anti-goat (1/10000) (sc-, Santa Cruz Biotechnology, Inc.) secondary antibodies were coupled to horseradish peroxidase revealing protein content by Pierce ECL Western Blotting Substrate (Thermo Scientific, Waltham, Massachusetts, USA). G3PDH $(0.05 \mu \mathrm{g} / \mathrm{ml})$ (G8795, Sigma) were used as cell protein loading control in cell membrane embedded proteins.

\subsection{Measurement of NO}

The production of NO was measured by quantification of its related end products, nitrite/nitrate in culture medium obtained as described above. In the assay, nitrate was converted to nitrite by nitrate reductase (EC 1.6.6.2) and total nitrite was measured using the Griess reaction [32]. Briefly, the samples were incubated with nitrate reductase $(0.2 \mathrm{U} / \mathrm{ml}), \mathrm{FAD}(5 \mathrm{mM})$ and NADPH $(50 \mathrm{mM})$ for $20 \mathrm{~min}$ at $37^{\circ} \mathrm{C}$. The reaction was stopped by the addition of sodium pyruvate $(10 \mathrm{mM})$ and lactate dehydrogenase $(24 \mathrm{mg} / \mathrm{ml})$ for $5 \mathrm{~min}$ at $37{ }^{\circ} \mathrm{C}$, and precipitated with $1.4 \% \mathrm{ZnSO}_{4}$. Total nitrite reacted with Griess reagent ( $1 \%$ sulfanilamide, $2.5 \% \mathrm{PO}_{4} \mathrm{H}_{3}, 0.1 \%$ n-naphthyl-ethylene-diamine) for $10 \mathrm{~min}$ at $37^{\circ} \mathrm{C}$, and was read at $540 \mathrm{~nm}$ using a Infinite 200 PRO Microplate Reader (TECAN).

The in situ production of NO was monitored using a fluorescent probe, such as DAF-FM diacetate (D-23842, Molecular Probes Europe BV, Leiden, The Netherlands), hydrolyzed by intracellular esterases to form DAF-FM in cytoplasm, and oxidized by NO to yield the highly fluorescent Triazole form (DAF-FM-T). Stock solution of DAF-FM diacetate was maintained in DMSO and stored at $-20^{\circ} \mathrm{C}$ until use. Cells were incubated with DAF-FM diacetate $(2.5 \mu \mathrm{M})$ for $30 \mathrm{~min}$ in culture medium. Cells were washed with PBS, in order to avoid any interference with the measurement of cell fluorescence. The production of NO was in situ assessed as the enhancement on the fluorescence at Ex $495 \mathrm{~nm} / \mathrm{Em} 515 \mathrm{~nm}$ measured using a Infinite 200 PRO Microplate Reader (TECAN). The corresponding controls were carried out in cells incubated in the presence/absence of solvent, dye and cells.
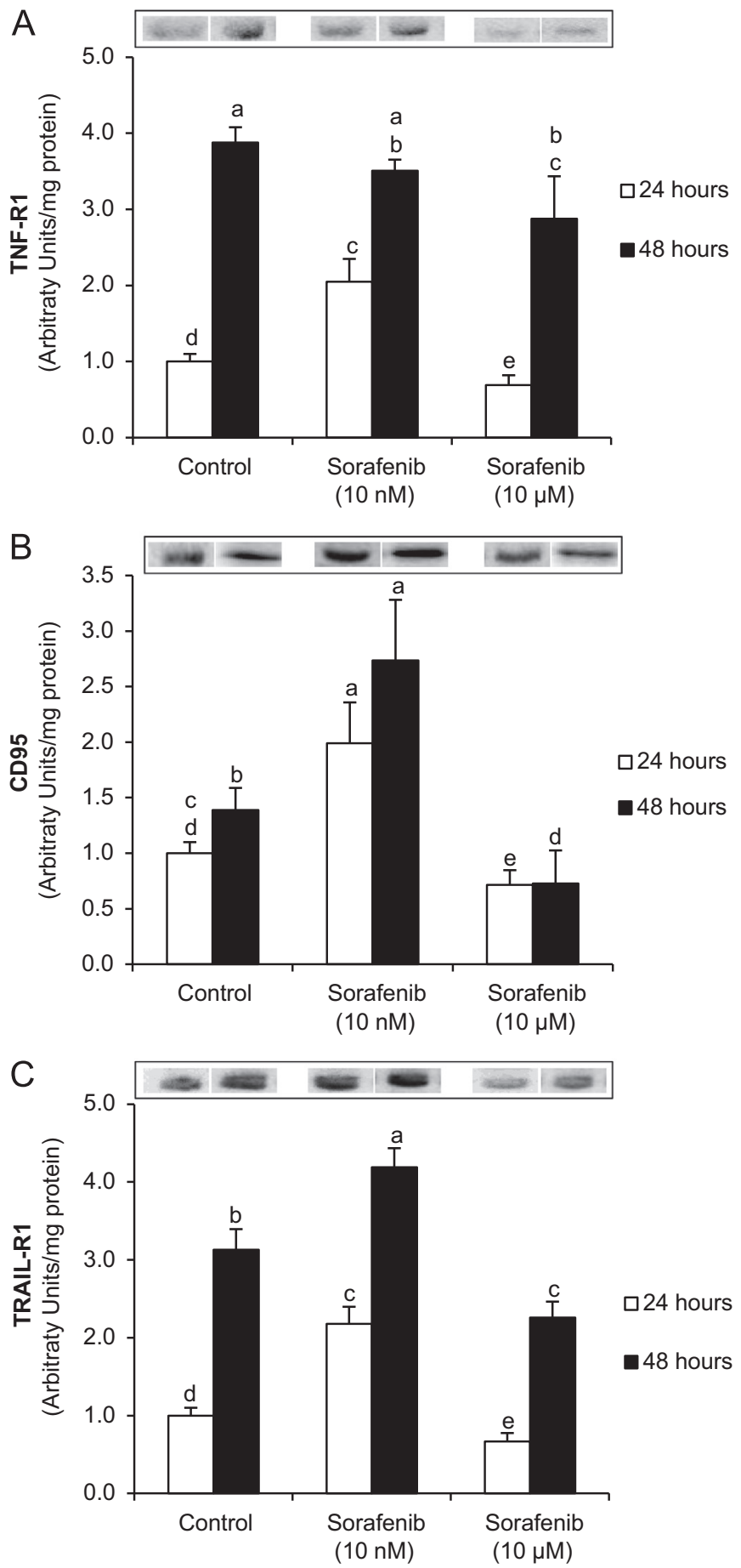

Fig. 1. Regulation of TNF-R1 (A), CD95 (B) and TRAIL-R1 (C) expression by Sorafenib in HepG2 cells. The expression of cell death receptors has been assessed by Western-blot analysis at 24 and $48 \mathrm{~h}$ after Sorafenib $(0,10 \mathrm{nM}$ and $10 \mu \mathrm{M})$ administration. GAPDH was used as internal protein loading. The statistical analysis of densitometric values of the spots is shown below the blot. Data are expressed as mean \pm SEM. The groups with different letters ( $a, b, c, d$ or e) were significantly different $(p \leq 0.05)$. The images are representative of six independent experiments.

2.6. Detection of S-nitrosylation in cell death receptors by the biotin switch assay

The procedure was performed as previously described [33] with recently described modifications [34]. Cells were treated with lysis solution (50 mM Tris- $\mathrm{HCl}$ pH 7.4, $300 \mathrm{mM} \mathrm{NaCl}, 5 \mathrm{mM}$ EDTA, $0.1 \mathrm{mM}$ neocuproine, $1 \%$ Triton $\mathrm{X}-100,5 \mu \mathrm{g} / \mathrm{mL}$ aprotinin and 
A

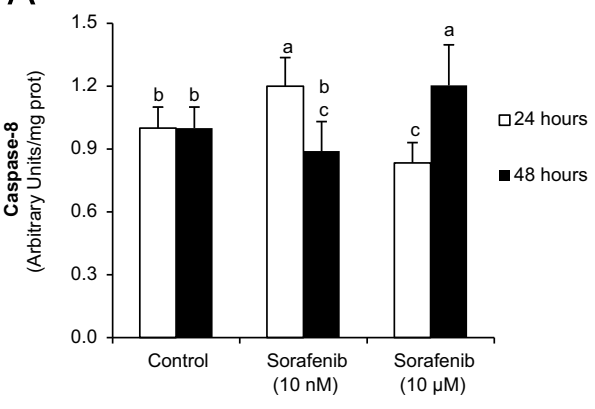

C

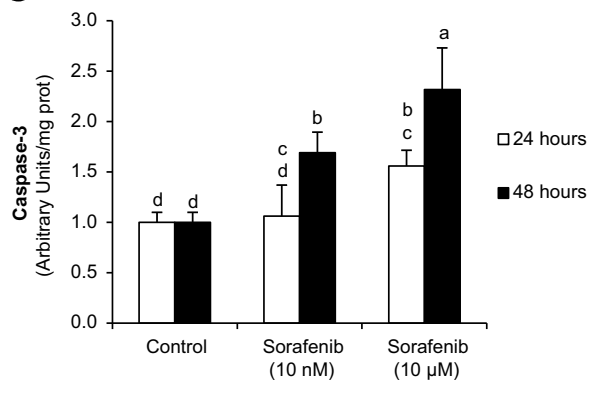

$D$
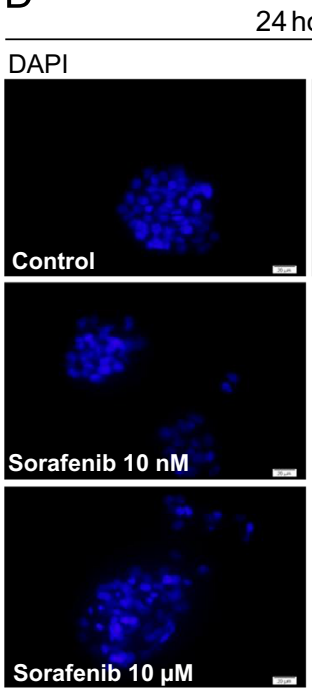

24 hours
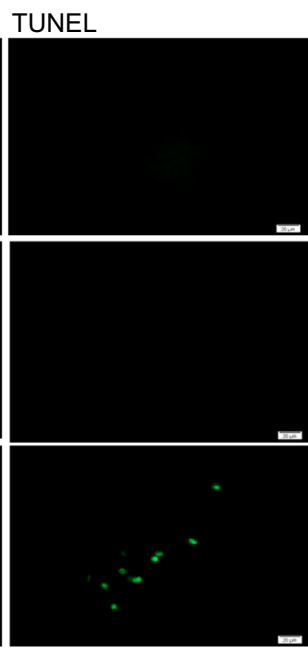

B

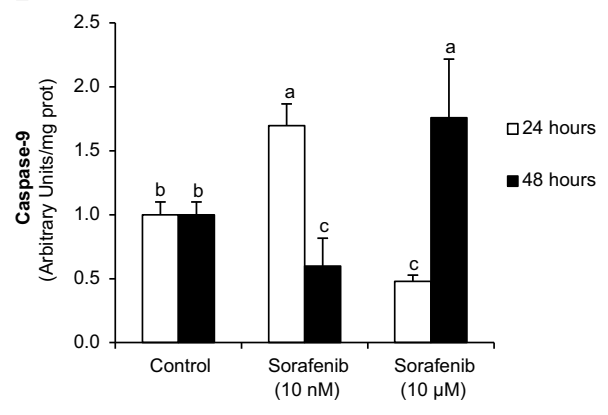

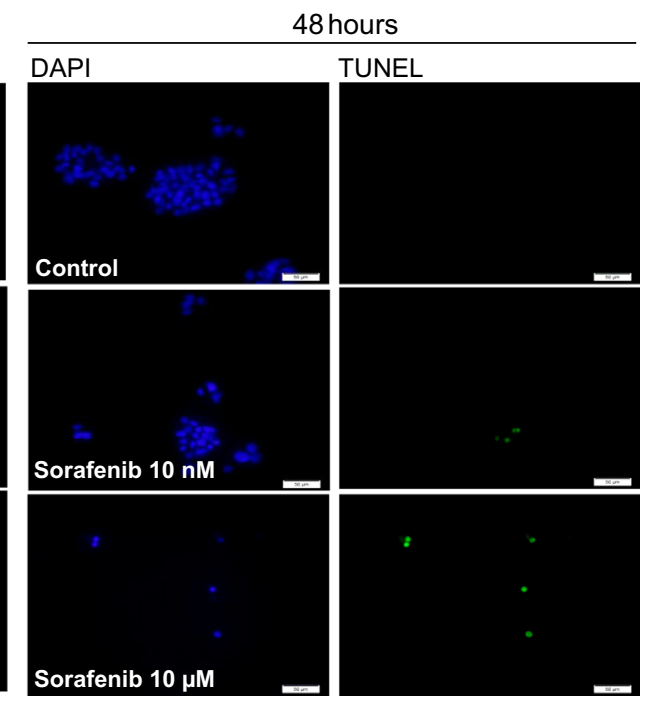

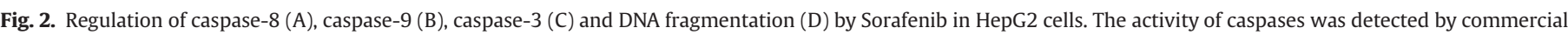

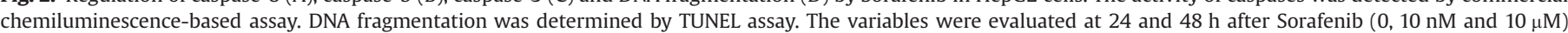

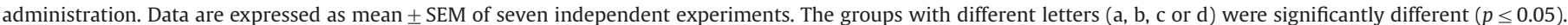
The images obtained from TUNEL assays are representative of three independent experiments.

$10 \mu \mathrm{g} / \mathrm{mL}$ leupeptin), and after centrifugation at $10,000 \mathrm{~g}$ the supernatants $(0.5 \mu \mathrm{g} / \mu \mathrm{L})$ were incubated with 4 volumes of blocking buffer (225 mM HEPES, pH 7.7, 0.9 mM EDTA, $90 \mu$ M neocuproine, $2.5 \%$ SDS and $20 \mathrm{mM}$ methyl methane thiosulfonate or MMTS) for $20 \mathrm{~min}$ at $50{ }^{\circ} \mathrm{C}$, and precipitated with $3-4$ volumes of cold acetone. The dried pellet was resuspended in $500 \mu \mathrm{L}$ HENS (HEN and $1 \%$ SDS) with $100 \mathrm{mM}$ sodium ascorbate and $167 \mu \mathrm{L} 4 \mathrm{mM}$ BiotinHPDP for $1 \mathrm{~h}$, precipitated with cold acetone, and dried pellet resuspended in $200 \mu \mathrm{L}$ HENS buffer and $800 \mu \mathrm{L}$ of neutralization buffer (20 mM HEPES pH 7.7, $100 \mathrm{mM} \mathrm{NaCl}, 1 \mathrm{mM}$ EDTA, $0.5 \%$ Triton X-100). Samples were treated with $45 \mu \mathrm{L}$ Neutravidin Plus UltralinK resin (Pierce) for $1 \mathrm{~h}$ in agitation, washed (20 mM HEPES $\mathrm{pH}$ 7.7, $600 \mathrm{mM} \mathrm{NaCl}, 1 \mathrm{mM}$ EDTA and $0.5 \%$ Triton X-100), and incubated in $20 \mathrm{mM}$ HEPES pH 7.7, $100 \mathrm{mM} \mathrm{NaCl}, 1 \mathrm{mM}$ EDTA, and $100 \mathrm{mM}$ 2-mercaptoethanol for $20 \mathrm{~min}$ at $37^{\circ} \mathrm{C}$. After centrifugation, supernatants were loaded into 10\% SDS-PAGE electrophoresis in reducing conditions. The expression of cell death receptors was detected by Western Blot analysis as described above.

\subsection{Statistical analysis}

Results are expressed as mean \pm SE of three (TUNEL and biotin switch assays), six (Western-blot images) and seven (caspase activities and NO-related measurements) independent experiments. Normal distribution was assessed by Shapiro-Wilk test. Homogeneity of variances was determined by Levene test. Data were compared using the analysis of variance with the Least Significant Difference's test as post-hoc multiple comparison analysis. The statistical differences were set at $p \leq 0.05$. The groups in the bar graphs showing different letters (a-e) were statistically different. 
A

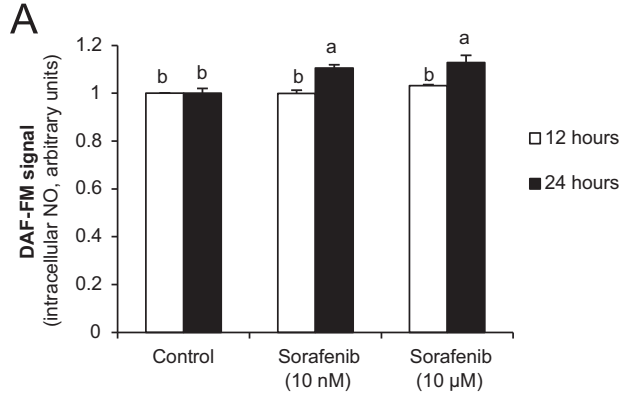

C

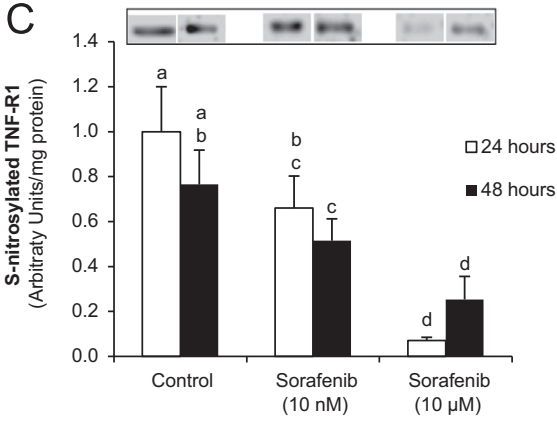

$\mathrm{B}$
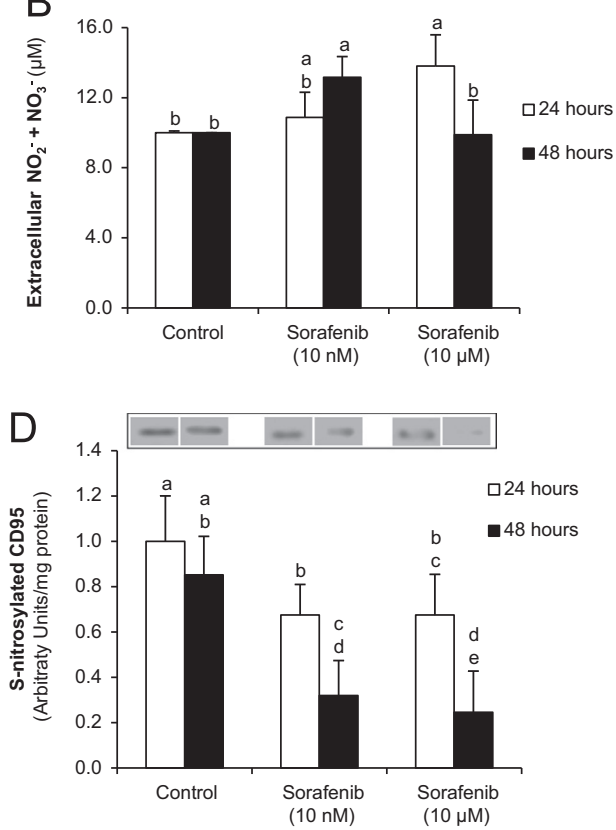

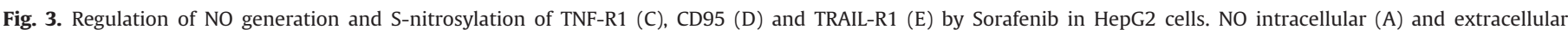

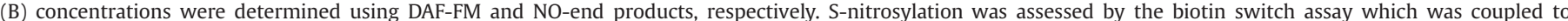

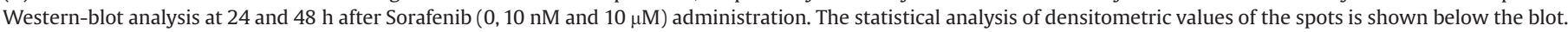

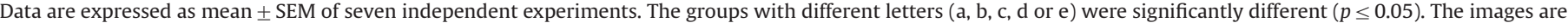
representative of three independent experiments (biotin switch) and six independent experiments (NO-related measurements).

\section{Results}

\subsection{Induction of apoptosis by Sorafenib}

Sorafenib increases cell death in hepatoma cells [26]. However, discrepancies exist between the involvement of extrinsic and intrinsic cell death pathway during Sorafenib-induced cell death $[28,35]$. Sorafenib dose-dependently regulated apoptotic cell signaling in hepatoblastoma cells. The expression of cell death receptors (TNF-R1, CD95 and TRAIL-R1) (Fig. 1), as well as caspase-8 (Fig. 2A) and -9 (Fig. 2B) activation was induced at $24 \mathrm{~h}$ after administration of Sorafenib at low concentration (10 nM). However, higher concentration of Sorafenib $(10 \mu \mathrm{M})$ reduced the above markers, and promoted the activation of downstream apoptotic markers such as caspase-3 (Fig. 2C) and TUNEL-staining (Fig. 2D) in HepG2 cells. Although the expression of cell death receptors (CD95 and TRAIL-R1) was still increased at low concentration of Sorafenib (10 nM), a significant rise of caspase-3 activity was observed that correlated with a reduction of caspase- 8 and -9 at $48 \mathrm{~h}$. High doses of Sorafenib $(10 \mu \mathrm{M})$ increased both extrinsic and intrinsic pathways at $48 \mathrm{~h}$ in HepG2 cells.

\subsection{Regulation of NO-generation and S-nitrosylation of cell death receptors by Sorafenib}

Sorafenib increased NO intracellular concentration measured by DAF-FM (Fig. 3A, $24 \mathrm{~h}$ ) and NO-end products in culture medium (Fig. 3B, $24 \mathrm{~h}$ ). The rise of NO-end product concentration was only observed at low Sorafenib concentration $(10 \mathrm{nM})$. The medium was replaced every $24 \mathrm{~h}$, so the measurement of NO-end product concentration in culture medium corresponds to its accumulation between $0-24 \mathrm{~h}$ and $24-48 \mathrm{~h}$. This fact may explain the reduction of NO-end product concentration in culture medium from cells treated with high dose of Sorafenib $(10 \mu \mathrm{M})$ at $48 \mathrm{~h}$ in which NO release appeared to be lower compared to that observed at 024 hours. Interestingly, this effect of the drug was related to a drastic dose-dependent reduction of S-nitrosylation in TNF-R1 (Fig. 3C) and CD95 (Fig. 3D). S-nitrosylation of TRAIL-R1 was not detected in the absence of NO donor (data not shown).

\subsection{Role of NO-donor on cell death in control and Sorafenib-treated hepatoblastoma cells}

The administration of NO donors increased the expression of cell death receptor in control cells (Fig. 4A), as well as S-nitrosylation of TNF-R1 (Fig. 4C), CD95 (Fig. 4D) and TRAIL-R1 (4E) in control cells. The estimation of S-nitrosylation/expression ratio showed that CSNO increased S-nitrosylation of cell death receptor stronger than NONOate in control cells (Fig. 4F). The administration of Sorafenib $(10 \mu \mathrm{M})$ changed the effect of NO donors in HepG2. In this sense, Sorafenib reduced the increase of cell death receptor expression induced by NO donors to values close to control levels (TNF-R1 and TRAIL-R1) (Fig. 4B), as well as the effect of NO donors on S-nitrosylation of cell death receptors (Fig. 4C-E) in HepG2 cells. Interestingly, the estimation of S-nitrosylation/ expression ratio showed that Sorafenib reduced S-nitrosylation of CD95 and TRAIL-R1 in NO donor-treated cells (Fig. 4G). The administration of NO donors increased caspase-8 (Fig. 5A), caspase-9 (Fig. 5B) and caspase-3 (Fig. 5C) in control and Sorafenib-treated cells.

\section{Discusion}

The biological activity of NO may be through cGMP-dependent and cGMP-independent pathways which play a relevant role in pathophysiological conditions [36]. NO induces cGMP-dependent protein kinases, cyclic-nucleotide-gated ion channels and cGMPregulated phosphodiesterases [6]. However, during the last decade cGMP-independent reactions gained considerable interest. A variety of effects are achieved through its interactions with targets via redox and additive chemistry, that may promote covalent 

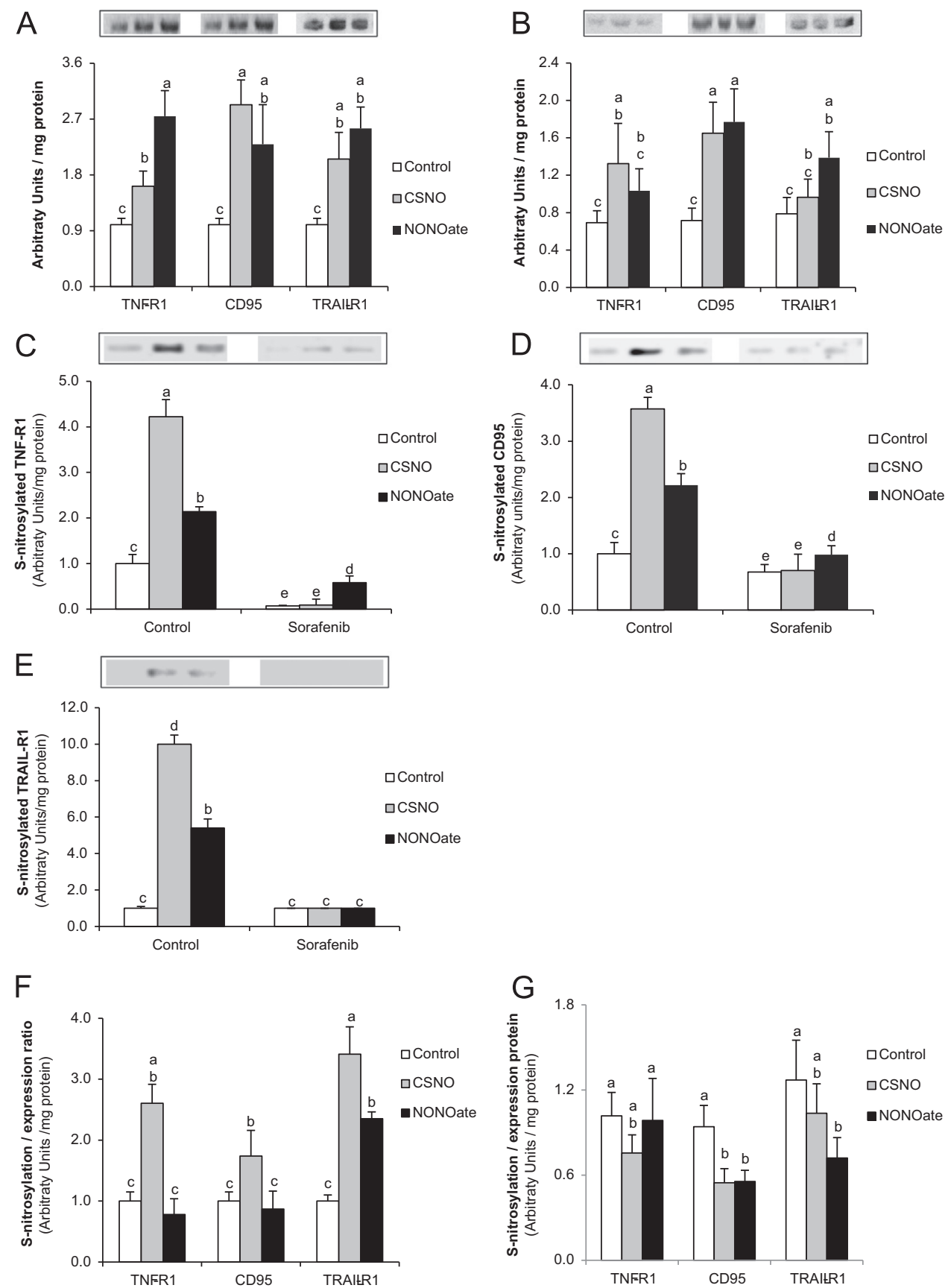

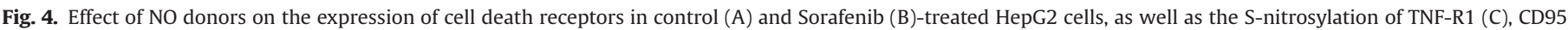

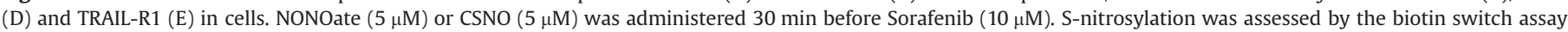

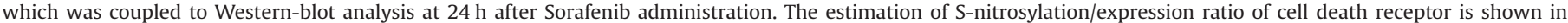

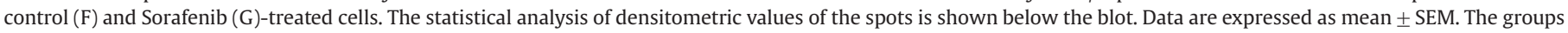
with different letters ( $\mathrm{a}, \mathrm{b}, \mathrm{c}, \mathrm{d}$ or e) were significantly different $(p \leq 0.05)$. The images are representative of three independent experiments.

modifications of intracellular proteins as well as oxidation events that do not require attachment of the NO group [37]. The most prominent and recognized NO reaction with thiols groups of cysteine residues is called S-nitrosylation or S-nitrosation, which leads to the formation of more stable nitrosothiols [38].

Several NO-dependent signal transduction pathways are related to protein S-nitrosylation, which in terms of cell death may exert either pro-apoptotic activity as a consequence of the alteration of mitochondrial potential and free radical generation [39], or anti-apoptotic such as GSNO- or thioredoxin-dependent S-nitrosylation of caspases [40], PKC $\varepsilon$ which reduces cFLIP release from DISC complex [41], and cFLIP avoiding its degradation through proteosomal degradation [42].

The key hallmarks of cancer cells are unlimited replicative potential, insensitivity to growth-inhibitory signals, evasion of apoptosis, cellular stress, and sustained angiogenesis, invasiveness and metastatic potential [7]. The alteration of cell death signaling is frequently observed in cancer [43-45]. The role of NO in tumor progression depends on the activity and localization of NOS isoforms, concentration and duration of NO exposure, cellular sensitivity, and hypoxia/re-oxygenation status [36]. The induction of nitrosative stress increases CD95 expression and cell death in pulmonary artery smooth muscle cells [46] and neurons [47]. We have recently shown that p53 mediates the increase of cell death 
A

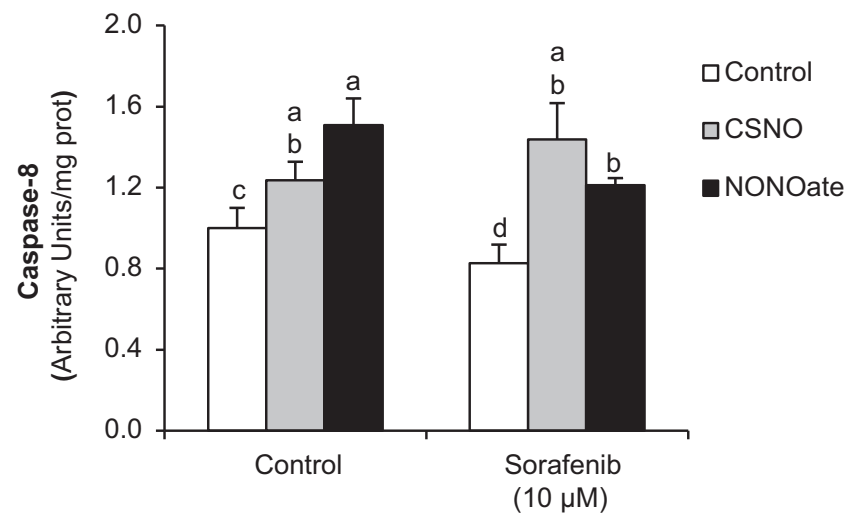

B

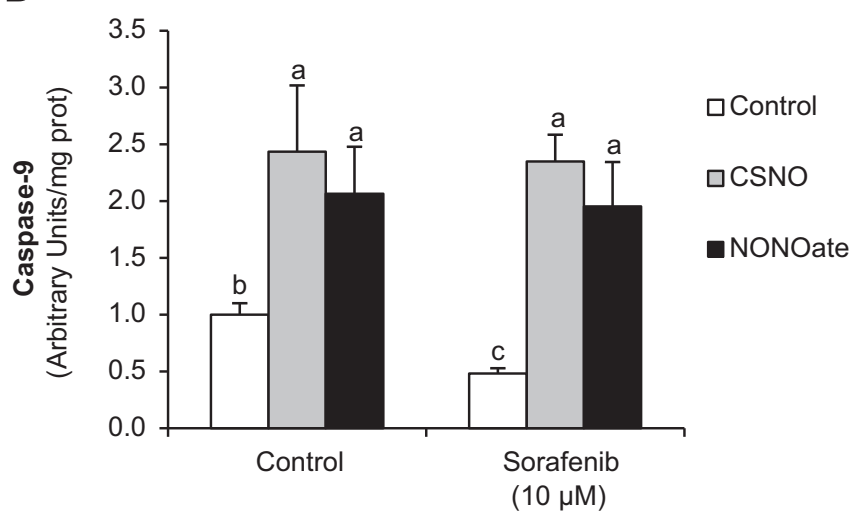

C

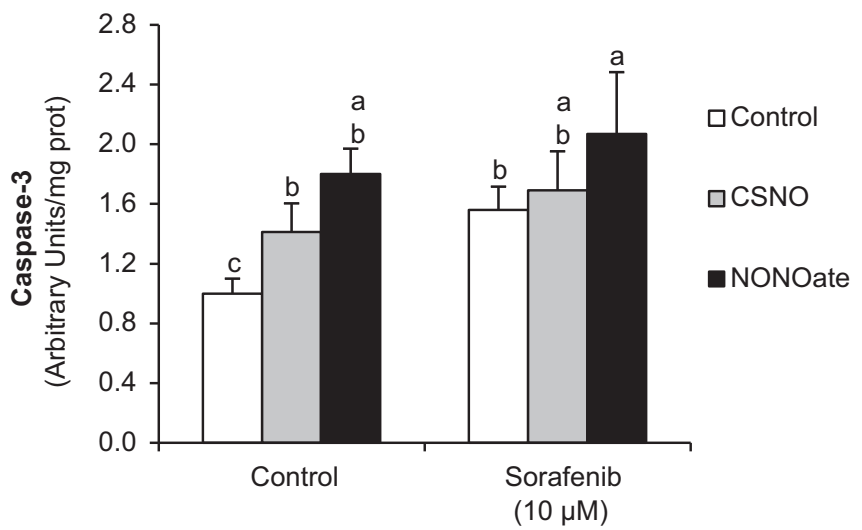

Fig. 5. Effect of NO donors on caspase-8 (A), caspase-9 (B) and caspase-3 (C) activation by Sorafenib in HepG2 cells. CSNO $(5 \mu \mathrm{M})$ or NONOate $(5 \mu \mathrm{M})$ was administered $30 \mathrm{~min}$ before Sorafenib. The activity of caspases was detected by commercial chemiluminescence-based assay at 24 after Sorafenib ( 0 and $10 \mu \mathrm{M})$ administration. Data are expressed as mean \pm SEM of seven independent experiments. The groups with different letters ( $a, b, c$ or d) were significantly different $(p \leq 0.05)$.

receptor expression and cell death induced by the exogenous administration of NO donor and/or NOS-3 overexpression in differentiated hepatoma cells lines [14]. In addition, S-nitrosylation of critical cysteine residues of CD95 modulates CD95 membrane trafficking and cell death stimulation in hepatoma cancer cells [18]. The induction of caspase- 8 activation was also related to S-nitrosylation of TRAIL-R1 in melanoma (A375), renal carcinoma $(\mathrm{ACHN})$, and ovarian carcinoma (NIH-OVCAR-3) cells treated with nitrosylcobalamin [48].

Sorafenib, a multi-kinase inhibitor which inhibits proliferation and angiogenesis, is the recommended treatment for patients with locally advanced/metastatic hepatocarcinoma [24,25]. Sorafenib exerts antitumoral activity targeting tyrosine kinase proliferating receptor, and on Raf-1 and B-Raf thus inhibiting RAF/MEK/ERK signaling pathway [49]. Although, Sorafenib increases apoptosis several discrepancies exist regarding the involvement of extrinsic or intrinsic pathways by Sorafenib in different tumor cell lines $[28,29]$.

The present study demonstrated that low concentration of Sorafenib (10 nM) was able to increase the expression of cell death receptors (TNF-R1, CD95 and TRAIL-R1) that correlated to high caspase- 8 and -9 activities but without significant increase of downstream apoptotic signaling such as caspase-3 activity and DNA fragmentation (Figs. 1 and 2). Interestingly, high Sorafenib concentration $(10 \mu \mathrm{M})$ reduced basal level of cell death receptor expression and caspase- 8 and -9 activation, but increased all those related to downstream apoptotic signaling at $24 \mathrm{~h}$ after administration. Caspase- 8 and -9 activities relapse at $48 \mathrm{~h}$ in cells treated with high Sorafenib concentration. The present study and other [30] have shown an increased NO production induced by Sorafenib in hepatoma cells. The administration of Sorafenib increased the intracellular NO concentration (DAF-FM) and in culture medium (NO-end products) that were related to reduction of S-nitrosylation of cell death receptors (TNF-R1 and CD95) (Fig. 3). This effect was particularly evident in cells treated with high Sorafenib concentration $(10 \mu \mathrm{M})$ at $24 \mathrm{~h}$. In these conditions, the expression of cell death receptors, as well as caspase- 8 and -9 activities were reduced compared to control level (Figs. 1 and 2). It were interesting to observe that the recovery of TNF-R1 and TRAIL-R1 expression, as well as caspase- 8 and -9 in cells treated with Sorafenib $(10 \mu \mathrm{M})$ (Figs. 1 and 2) were related to a recovery of S-nitrosylation of TNF-R1 (Fig. 3) at 48 h. Our data suggest that Sorafenib might transitorily activate denitrosylating-like activity. Thioredoxin-1 has been shown to actively denitrosylated cytosolic caspase-3 and thereby maintains a low steady-state amount of S-nitrosylation [50]. CSNO treatment also increased S-nitrosoglutathione reductase (GSNOR) activity that reduces SNO content in human hepatocytes [51].

The administration of low concentrations of NO donor such as CSNO and NONOate $(5 \mu \mathrm{M})$ induced a permissive induction of cell death (up to $48 \mathrm{~h}$ ). This experimental approach allows us to combine NO donor and Sorafenib treatments. NO donors drastically induced S-nitrosylation of cell death receptors and increased caspase-8, caspase- 9 and caspase- 3 activities in control cells. The estimation of S-nitrosylation/expression ratio showed that CSNO was more effective than NONOate inducing S-nitrosylation of cell death receptor (Fig. 4E). This could be due to the characteristic of CSNO molecule, which is a permeable nitrosothiol whose effect in the induction of S-nitrosylation is more efficient than NONOate. However, this difference was not accompanied with a reduction of caspase- 8 and -9 activation by NONOate compared to CSNO treatment. Sorafenib $(10 \mu \mathrm{M})$ reduced the expression of cell death receptors and their S-nitrosylation of cell death receptors (TNF-R1 and CD95) compared to the level observed in control and NO donor-treated HepG2 cells (Figs. 1, 3, 4B-E). Interestingly, Sorafenib $(10 \mu \mathrm{M})$ reduced the estimated value of S-nitrosylation/expression ratio in NO donor-treated cells. S-nitrosylation of cell death receptors seems to be relevant for their trafficking to lipid raft and induction of apoptosis in hepatocytes [18]. In concordance, the reduction of cell death receptor S-nitrosylation by Sorafenib was related to a reduction of caspase- 8 and -9 , but a relevant increase of caspase- 3 in HepG2 cells ( $24 \mathrm{~h}$ ). The presence of NO generation system in cell membrane may be relevant for cell signaling. In this sense, the antitumoral properties of NOS-3 observed by our group [14,52] may be reinforced by its localization in lipid raft domains or caveolae fraction [53]. In this sense, the extrinsic cell death signaling has been shown to be regulated by 
caveolin-1, a specific protein of lipid raft compartment, in physiopathological cellular conditions [54-56].

The present study suggests that the down-regulation of S-nitrosylation of cell death receptors by Sorafenib may be critical to reinforce its downstream pro-apoptotic properties of the drug overwhelming upstream survival pathways in hepatoma cells. More studies will allow the identification of potential denitrosylating activity induced by Sorafenib which may affect the trafficking or activity of cell death receptors into lipid raft in hepatoblastoma cells.

\section{Acknowledgments}

We thank the Instituto de Salud Carlos III (PI13/00021), Spanish Ministry of Economy and Competitiveness (BFU2012-32056), Consejería Economía, Innovación, Ciencia y Empleo, Junta de Andalucia (BIO-0216 and CTS-6264) and Consejería de Salud (PI13/ 00025) for its financial support. We thank Biomedical Research Network Center for Liver and Digestive Diseases (CIBERehd) founded by Instituto de Salud Carlos III.

\section{References}

[1] J.R. Lancaster Jr., A tutorial on the diffusibility and reactivity of free nitric oxide, Nitric Oxide 1 (1997) 18-30.

[2] W.K. Alderton, C.E. Cooper, R.G. Knowles, Nitric oxide synthases: structure, function and inhibition, Biochem. J. 357 (2001) 593-615.

[3] H. Yasuda, K. Nakayama, M. Watanabe, S. Suzuki, H. Fuji, S. Okinaga, et al., Nitroglycerin treatment may enhance chemosensitivity to docetaxel and carboplatin in patients with lung adenocarcinoma, Clin. Cancer Res. 12 (2006) 6748-6757.

[4] D.R. Siemens, J.P. Heaton, M.A. Adams, J. Kawakami, C.H. Graham, Phase II study of nitric oxide donor for men with increasing prostate-specific antigen level after surgery or radiotherapy for prostate cancer, Urology 74 (2009) 878-883.

[5] P.K. Lala, C. Chakraborty, Role of nitric oxide in carcinogenesis and tumour progression, Lancet Oncol. 2 (2001) 149-156.

[6] J. Muntane, M.D. la Mata, Nitric oxide and cancer, World J. Hepatol. 2 (2010) $337-344$.

[7] J. Luo, N.L. Solimini, S.J. Elledge, Principles of cancer therapy: oncogene and non-oncogene addiction, Cell 136 (2009) 823-837.

[8] G.I. Evan, K.H. Vousden, Proliferation, cell cycle and apoptosis in cancer, Nature 411 (2001) 342-348.

[9] F.H. Igney, P.H. Krammer, Death and anti-death: tumour resistance to apoptosis, Nat. Rev. Cancer 2 (2002) 277-288.

[10] C.H. Weber, C. Vincenz, The death domain superfamily: a tale of two interfaces? Trends Biochem. Sci. 26 (2001) 475-481.

[11] J.L. Bodmer, P. Schneider, J. Tschopp, The molecular architecture of the TNF superfamily, Trends Biochem. Sci. 27 (2002) 19-26.

[12] S. Fulda, K.M. Debatin, Exploiting death receptor signaling pathways for tumor therapy, Biochim. Biophys. Acta 1705 (2004) 27-41.

[13] A. Ashkenazi, V.M. Dixit, Death receptors: signaling and modulation, Science 281 (1998) 1305-1308.

[14] R. Gonzalez, G. Ferrin, P. Aguilar-Melero, I. Ranchal, C.I. Linares, R.I. Bello, et al. Targeting hepatoma using nitric oxide donor strategies, Antioxid. Redox Signal. 18 (2013) 491-506.

[15] A. Millet, A. Bettaieb, F. Renaud, L. Prevotat, A. Hammann, E. Solary, et al., Influence of the nitric oxide donor glyceryl trinitrate on apoptotic pathways in human colon cancer cells, Gastroenterology 123 (2002) 235-246.

[16] A. Eberle, R. Reinehr, S. Becker, V. Keitel, D. Haussinger, CD95 tyrosine phosphorylation is required for CD95 oligomerization, Apoptosis 12 (2007) 719-729.

[17] R. Reinehr, B. Gorg, A. Hongen, D. Haussinger, CD95-tyrosine nitration inhibits hyperosmotic and CD95 ligand-induced CD95 activation in rat hepatocytes, J. Biol. Chem. 279 (2004) 10364-10373.

[18] L. Leon-Bollotte, S. Subramaniam, O. Cauvard, S. Plenchette-Colas, C. Paul, C. Godard, et al., S-nitrosylation of the death receptor fas promotes fas ligandmediated apoptosis in cancer cells, Gastroenterology 140 (2011) 2009-2018 (2018.e2001-2004).

[19] I. Herr, D. Wilhelm, T. Bohler, P. Angel, K.M. Debatin, Activation of CD95 (APO1/Fas) signaling by ceramide mediates cancer therapy-induced apoptosis, EMBO J. 16 (1997) 6200-6208.

[20] O. Micheau, A. Hammann, E. Solary, M.T. Dimanche-Boitrel, STAT-1-independent upregulation of FADD and procaspase- 3 and -8 in cancer cells treated with cytotoxic drugs, Biochem. Biophys. Res. Commun. 256 (1999) 603-607.
[21] M.C. Ruiz-Ruiz, A. Lopez-Rivas, p53-mediated up-regulation of CD95 is not involved in genotoxic drug-induced apoptosis of human breast tumor cells, Cell Death Differ. 6 (1999) 271-280.

[22] C. Friesen, I. Herr, P.H. Krammer, K.M. Debatin, Involvement of the CD95 (APO$1 /$ FAS) receptor/ligand system in drug-induced apoptosis in leukemia cells, Nat. Med. 2 (1996) 574-577.

[23] M. Muller, S. Strand, H. Hug, E.M. Heinemann, H. Walczak, W.J. Hofmann, et al., Drug-induced apoptosis in hepatoma cells is mediated by the CD95 (APO-1/ Fas) receptor/ligand system and involves activation of wild-type p53, J. Clin. Invest. 99 (1997) 403-413.

[24] A.L. Cheng, Y.K. Kang, Z. Chen, C.J. Tsao, S. Qin, J.S. Kim, et al., Efficacy and safety of sorafenib in patients in the Asia-Pacific region with advanced hepatocellular carcinoma: a phase III randomised, double-blind, placebo-controlled trial, Lancet Oncol. 10 (2009) 25-34.

[25] J.M. Llovet, S. Ricci, V. Mazzaferro, P. Hilgard, E. Gane, J.F. Blanc, et al., Sorafenib in advanced hepatocellular carcinoma, N. Engl. J. Med. 359 (2008) 378-390.

[26] J. Fernando, P. Sancho, C.M. Fernandez-Rodriguez, J.L. Lledo, L. Caja, J. S. Campbell, et al., Sorafenib sensitizes hepatocellular carcinoma cells to physiological apoptotic stimuli, J. Cell. Physiol. 227 (2012) 1319-1325.

[27] K.F. Chen, W.T. Tai, T.H. Liu, H.P. Huang, Y.C. Lin, C.W. Shiau, et al., Sorafenib overcomes TRAIL resistance of hepatocellular carcinoma cells through the inhibition of STAT3, Clin. Cancer Res. 16 (2010) 5189-5199.

[28] R.R. Rosato, J.A. Almenara, S. Coe, S. Grant, The multikinase inhibitor sorafenib potentiates TRAIL lethality in human leukemia cells in association with Mcl-1 and cFLIPL down-regulation, Cancer Res. 67 (2007) 9490-9500.

[29] G. Zhang, M.A. Park, C. Mitchell, H. Hamed, M. Rahmani, A.P. Martin, et al. Vorinostat and sorafenib synergistically kill tumor cells via FLIP suppression and CD95 activation, Clin. Cancer Res. 14 (2008) 5385-5399.

[30] R. Coriat, C. Nicco, C. Chereau, O. Mir, J. Alexandre, S. Ropert, et al., Sorafenibinduced hepatocellular carcinoma cell death depends on reactive oxygen species production in vitro and in vivo, Mol. Cancer Ther. 11 (2012) 2284-2293.

[31] D. Jourd'heuil, L. Gray, M.B. Grisham, S-nitrosothiol formation in blood of lipopolysaccharide-treated rats, Biochem. Biophys. Res. Commun. 273 (2000) $22-26$.

[32] L.C. Green, D.A. Wagner, J. Glogowski, P.L. Skipper, J.S. Wishnok, S. R. Tannenbaum, Analysis of nitrate, nitrite, and [15N]nitrate in biological fluids, Anal. Biochem. 126 (1982) 131-138.

[33] A. Martinez-Ruiz, S. Lamas, Detection and identification of S-nitrosylated proteins in endothelial cells, Methods Enzymol. 396 (2005) 131-139.

[34] M.T. Forrester, M.W. Foster, J.S. Stamler, Assessment and application of the biotin switch technique for examining protein S-nitrosylation under conditions of pharmacologically induced oxidative stress, J. Biol. Chem. 282 (2007) 13977-13983.

[35] W. Zhang, M. Konopleva, V.R. Ruvolo, T. McQueen, R.L. Evans, W.G. Bornmann, et al., Sorafenib induces apoptosis of AML cells via Bim-mediated activation of the intrinsic apoptotic pathway, Leukemia 22 (2008) 808-818.

[36] J. Muntane, A.J. De la Rosa, L.M. Marin, F.J. Padillo, Nitric oxide and cell death in liver cancer cells, Mitochondrion 13 (2013) 257-262.

[37] D.T. Hess, A. Matsumoto, S.O. Kim, H.E. Marshall, J.S. Stamler, Protein S-nitrosylation: purview and parameters, Nat. Rev. Mol. Cell Biol. 6 (2005) $150-166$.

[38] S.R. Jaffrey, H. Erdjument-Bromage, C.D. Ferris, P. Tempst, S.H. Snyder, Protein S-nitrosylation: a physiological signal for neuronal nitric oxide, Nat. Cell Biol. 3 (2001) 193-197.

[39] H. Vieira, G. Kroemer, Mitochondria as targets of apoptosis regulation by nitric oxide, IUBMB Life 55 (2003) 613-616.

[40] S.R. Tannenbaum, J.E. Kim, Controlled S-nitrosation, Nat. Chem. Biol. 1 (2005) $126-127$.

[41] P.R. Dash, J. McCormick, M.J. Thomson, A.P. Johnstone, J.E. Cartwright, G. S. Whitley, Fas ligand-induced apoptosis is regulated by nitric oxide through the inhibition of fas receptor clustering and the nitrosylation of protein kinase Cepsilon, Exp. Cell Res. 313 (2007) 3421-3431.

[42] P. Chanvorachote, U. Nimmannit, L. Wang, C. Stehlik, B. Lu, N. Azad, et al. Nitric oxide negatively regulates Fas CD95-induced apoptosis through inhibition of ubiquitin-proteasome-mediated degradation of FLICE inhibitory protein, J. Biol. Chem. 280 (2005) 42044-42050.

[43] K. Higaki, H. Yano, M. Kojiro, Fas antigen expression and its relationship with apoptosis in human hepatocellular carcinoma and noncancerous tissues, Am. J. Pathol. 149 (1996) 429-437.

[44] S.H. Lee, M.S. Shin, H.S. Lee, J.H. Bae, H.K. Lee, H.S. Kim, et al., Expression of Fas and Fas-related molecules in human hepatocellular carcinoma, Hum. Pathol. 32 (2001) 250-256.

[45] K. Piras-Straub, K. Khairzada, M. Trippler, H.A. Baba, G.M. Kaiser, A. Paul, et al., TRAIL expression levels in human hepatocellular carcinoma have implications for tumor growth, recurrence and survival, Int. J. Cancer 136 (2015) E154-E160.

[46] M.A. Hayden, P.A. Lange, D.K. Nakayama, Nitric oxide and cyclic guanosine monophosphate stimulate apoptosis via activation of the Fas-FasL pathway, J. Surg. Res. 101 (2001) 183-189.

[47] L.J. Martin, K. Chen, Z. Liu, Adult motor neuron apoptosis is mediated by nitric oxide and Fas death receptor linked by DNA damage and p53 activation, J. Neurosci. 25 (2005) 6449-6459.

[48] Z. Tang, J.A. Bauer, B. Morrison, D.J. Lindner, Nitrosylcobalamin promotes cell death via S nitrosylation of Apo2L/TRAIL receptor DR4, Mol. Cell Biol. 26 (2006) 5588-5594. 
[49] B. Zhai, X.Y. Sun, Mechanisms of resistance to sorafenib and the corresponding strategies in hepatocellular carcinoma, World J. Hepatol. 5 (2013) 345-352.

[50] M. Benhar, M.T. Forrester, D.T. Hess, J.S. Stamler, Regulated protein denitrosylation by cytosolic and mitochondrial thioredoxins, Science 320 (2008) 1050-1054.

[51] L.M. Lopez-Sanchez, F.J. Corrales, R. Gonzalez, G. Ferrin, J.R. Munoz-Castaneda, I. Ranchal, et al., Alteration of S-nitrosothiol homeostasis and targets for protein S-nitrosation in human hepatocytes, Proteomics 8 (2008) 4709-4720.

[52] P. Aguilar-Melero, G. Ferrin, J. Muntane, Effects of nitric oxide synthase-3 overexpression on post-translational modifications and cell survival in HepG2 cells, J. Proteomics 75 (2012) 740-755.
[53] G. Garcia-Cardena, P. Martasek, B.S. Masters, P.M. Skidd, J. Couet, S. Li, et al., Dissecting the interaction between nitric oxide synthase (NOS) and caveolin. Functional significance of the nos caveolin binding domain in vivo, J. Biol. Chem. 272 (1997) 25437-25440.

[54] H.E. Saqr, O.M. Omran, J.L. Oblinger, A.J. Yates, TRAIL-induced apoptosis in U-1242 MG glioma cells, J. Neuropathol. Exp. Neurol. 65 (2006) 152-161.

[55] X. Zhao, Y. Liu, Q. Ma, X. Wang, H. Jin, M. Mehrpour, et al., Caveolin-1 negatively regulates TRAIL-induced apoptosis in human hepatocarcinoma cells, Biochem. Biophys. Res. Commun. 378 (2009) 21-26.

[56] Y.G. Ko, J.S. Lee, Y.S. Kang, J.H. Ahn, J.S. Seo, TNF-alpha-mediated apoptosis is initiated in caveolae-like domains, J. Immunol. 162 (1999) 7217-7223. 